\title{
Martha Kneale on Why Metaphysical Necessities Are Not A Priori*
}

\begin{abstract}
In her I938 paper 'Logical and Metaphysical Necessity', Martha Kneale introduces the necessary a posteriori. I present a critical summary of Kneale's argument that so-called 'metaphysical propositions' are necessary but not a priori. I argue that Kneale is well placed to offer a template for reconciling conceivability approaches to modal epistemology with the post-Kripkean trend for taking metaphysical necessities to have their source in mind-independent reality.
\end{abstract}

KEYWORDS: metaphysics, epistemology, necessary a posteriori, philosophy of logic, history of philosophy

\section{A Simple Story}

Can we know all metaphysical necessities a priori, or are some (or all) only knowable a posteriori? There is a familiar, simplified story of the changing answers to this

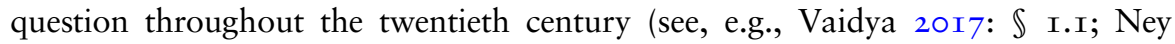
20I4: 2I0; Bird 20IO: I25-26). That story goes something like this.

In the first half of the twentieth century, the philosophical school of logical empiricism was a guiding force (see, e.g., Ayer I936; Wittgenstein [I92 I] I974; Stadler and Uebel 20I2). According to the received wisdom, necessity, analyticity, and a priority go hand in hand. Something is necessarily true if, and only if, it is true in virtue of its meaning, and we can therefore know all and only such truths a priori, via our knowledge of the meaning of the words expressing them. Such truths (and knowledge) are clearly distinguished from empirical fact (and empirical knowledge). To know-even to grasp-empirical truths, we need particular experience of the world. As the century wore on, philosophy grew away from logical empiricism, but this assumption concerning the co-extension of necessity, analyticity and a priority remained largely unchallenged (except for a challenge to the very legitimacy of those notions, which itself arguably trades on their coextension [Quine I95 I; I953]). Then, in January I970, a revolution was started. Saul Kripke gave three lectures at Princeton University, later published as Naming and Necessity. Amongst other things, in these lectures Kripke argues that some (metaphysical) necessities are knowable only a posteriori. This was a

\footnotetext{
* This article is the fifth in a special series of commissioned articles on women in the history of philosophy. The fourth article 'Elizabeth Hamilton's Scottish Associationism: Early Nineteenth-Century Philosophy of Mind', by Samin Gokcekus, appeared in Volume 5, Issue 3, pp. 267-285.

I thank audiences in Bristol and London; Mike Beaney, Bill Brewer, Sarah Sawyer, and Mark Textor; and two anonymous referees for helpful comments on previous versions of this article.
} 
tremendous watershed moment in the history of philosophy in general, and the history of logic and metaphysics in particular. From that time onwards, the consensus has been that Kripke is right, or that disagreement warrants serious engagement with his arguments. Metaphysical necessity is one thing, the a priori is another, and they overlap only partially, if at all.

The story corresponds to a changing conception of the nature and source of metaphysical necessity. Given this changing picture, it is difficult to characterize metaphysical necessity in neutral terms. At least, metaphysical necessity is a variety of alethic necessity: if it is metaphysically necessary that $p$ then $p$. It is typically taken to be absolute-if it is metaphysically necessary that $p$, then for any alethic sense of 'necessary', it is necessary that $p$ in that sense. The starting point of our simple story goes naturally with a kind of conventionalism about necessity: necessity is not merely co-extensive with analyticity, but has its source in analyticity, which in turn depends upon linguistic convention. As such, given that one can know analytic truths a priori by conceptual analysis, one is guaranteed $a$ priori knowledge of necessities. If one instead takes metaphysical necessity to have its source in worldly-nonrepresentational-things, as is now more common, then the link to analyticity and a priority seems obviously weakened. Hence, nowadays metaphysical necessity is sometimes even defined as also being synthetic and/or $a$ posteriori (e.g., Rosen 2006: I 5-I6).

This is a simplified story, and simplified stories are usually incorrect in all sorts of ways. My present aim is to raise one particular challenge to this story, centering on a paper, 'Logical and Metaphysical Necessity', presented by Martha Kneale at the Aristotelian Society in London in June I938 (and subsequently published in the Proceedings). In that paper, Kneale introduces the necessary a posteriori. Hence, already in the I930s there is a serious challenge to the co-extension of necessity and a priority.

I proceed as follows. First, I present a critical account of Kneale's argument that so-called 'metaphysical propositions' are necessary but not a priori. I then move on to compare Kneale and Kripke. I argue that there are important and interesting similarities between the two. Both reject a certain kind of linguistic account of metaphysical necessities, which leads them, one way or another, to conclude that such necessities are not a priori. Both appeal to aspects of the world to explain these necessities, and why we need empirical experience to discover them. Moreover-perhaps surprisingly-both appear to endorse a conceivability principle. I argue that Kneale is better placed to defend the use of such a principle, and as such, offers a template for a reconciliation of conceivability approaches to modal epistemology with the post-Kripkean trend for taking metaphysical necessities to have their source in mind-independent reality.

\section{Metaphysical Propositions}

Kneale's discussion centers on an important class of propositions: metaphysical propositions. First, to briefly sketch the framework that emerges throughout the paper: Propositions can be true or false, necessary, possible, or impossible. Sentences can also be true or false, necessarily or possibly true etc., and they 
express propositions (see Kneale I938:258-6I). I assume, then, that the alethic and modal properties of sentences are inherited from the propositions they express. Propositions can state facts (Kneale I938: 266).

Kneale asks,

[a]re there metaphysically necessary propositions and, if so, which are they and how are they to be distinguished from other necessary propositions, e.g., logically necessary propositions? (Kneale I938: 253)

This question arises due to a fallacy of equivocation over modal terms that Kneale diagnoses as afflicting the master argument of Diodorus Cronus, the details of which do not concern me here (Kneale 1938: 253). She then introduces metaphysical propositions:

Metaphysical propositions are distinguished from empirical propositions by the fact that they are necessary, i.e., their contradictories are inconceivable and from logical propositions by the fact that they are synthetic, i.e., their contradictories are not self-contradictory. (Kneale I93 8: 264)

They are metaphysical because they are concerned with the most general characteristics of reality:

I think they may justifiably be called metaphysical, for if there is a science which is concerned with the most general characteristics of reality and the necessary relations between them, these propositions belong to it. And such a science has traditionally been called metaphysics. (Kneale I938: 264)

Consider the first point: that metaphysical propositions are necessary. Necessity is equated with inconceivability (Kneale I93 8: 263). Rather than directly appeal to a connection between possibility and conceivability, Kneale draws a connection between necessity and the inconceivability of the opposite. This resembles what Crispin Wright has called the 'counter-conceivability principle' (see also Wright 2002):

If one has what at least appears to be a lucid, detailed conception of how it might be that not $P$, then that should count as a good, albeit defeasible ground for its being possible that not $P$, and hence its not being necessary that $P$, whatever the subject matter of $P$. (Wright 20I8: 268)

Such a principle is a special case of the standard conceivability principle-if it is conceivable that $p$ then it is possible that $p$-where $p$ is of the form not- $q$. But it draws out the particular relevance of conceivability for claims of metaphysical necessity. For it follows, by contraposition, that if it is impossible that not- $q$ (necessary that $q$ ), then it is inconceivable that not- $q$. 
We might question why metaphysical necessity should be allied to such a principle. For, is not the point precisely that metaphysical necessity runs free of our conceptual resources, in which case, a counter-conceivability principle should provide no guide to metaphysical necessity at all? Indeed, I argue below that Kneale's account of metaphysically necessary propositions, and how we can know them, still draws on a connection to our grasp of their meaning, but their meaning bears an important relation to the empirical facts, hence Kneale has the resources to defend her commitment to a conceivability principle.

What are Kneale's examples of metaphysical propositions? Kneale begins with a discussion of rules for tense (partly to illuminate the necessity of the past implicated in the master argument.) She presents the rules in two different ways, depending on whether one takes tense to reside in the sentences expressing at different times tenseless propositions, or whether one allows the propositions themselves to be tensed. For example, under the first view, that 'all propositions are true or false and do not change their truth-values' and 'the same proposition is at different times appropriately or correctly expressible by different sentences' (26I):

Rule I.-The standard sentence ['There is (timeless) at least one A.'] entails a disjunction of sentences, i.e., either there was an A or there is an A or there will be an A....

Rule 4.-If any sentence of the form, 'There was an A' is at any moment the correct expression of a true proposition, an exactly similar sentence will be at all succeeding moments the correct expression of a true proposition.

(Kneale I938: 262)

Under the second view, according to which 'tense and the other elements mentioned above are part of the structure of some historical propositions' (262), we have the corresponding rules:

Rule $\mathrm{I}$. - If a standard proposition of the form 'There is at least one A' is true, it follows that at any given moment one of the following propositions is true; 'There will be an A', 'There is an A', 'There was an A'.

Rule 4.-If any proposition of the form, 'There was an A' is at any moment true, it follows that the same proposition will be true at all succeeding moments.

(Kneale I938: 263)

It is plausible that the contradictories of these rules are not self-contradictory:

We cannot imagine a language which uses tenses at all in which these rules concerning tenses do not apply, or, to state this without reference 
to language, we cannot imagine a universe which is temporal at all in which these propositions concerning the truth and falsity of propositions about the past, present and future are not true.

But these propositions do not seem to be necessary in the sense of being analytic. As far as I can see, their contradictories are not self-contradictory. "There was an A' is true and will be false', does not seem to be self-contradictory in the way in which 'There was an A' is both true and false' is. (Kneale I938: 263)

Claims about imaginative ability aside, it seems plausible that part of the nature of temporality is some kind of linear ordering of past, present and future. And although these temporal features are encoded pretty effectively into tensed language, it is not at all clear that impossible combinations of tense-as in Kneale's example-yield formal contradictions. For present purposes, then, I shall grant these examples. Further examples are 'propositions concerning spatial inclusion and betweenness' and 'propositions concerning the relations between colours and similar propositions concerning the relations between other sensory qualities of the same range' (Kneale I938: 266), such as 'red is more like pink than it is like yellow'.

Kneale connects these cases to Isaiah Berlin's discussion of ostensive definitions, presented the previous year at the Aristotelian Society. The background consensus at the time was that meaningful propositions are either tautologies or empirical propositions. The former are necessary, analytic and a priori, the latter contingent, synthetic, and a posteriori. There is also agreement that the contradictories of logically necessary propositions are self-contradictory, that logically necessary propositions are a priori, and that logical truth and analytic truth are to be understood in terms of linguistic convention. Berlin aimed to show that there are $a$ priori propositions other than those whose contradictories are self-contradictory, i.e., other than analytic or logical truths.

Of course, Berlin's and Kneale's were not the only voices of dissent at the time. See, for example, A. C. Ewing's (I940) blistering attack on conventionalist theories of the a priori. I do not have space for a thorough review of all such dissent here. But it is worth stressing that while others, such as Berlin and Ewing, challenged links between a priority and analyticity, Kneale stands apart by challenging the link between a priority and necessity. Hence, my focus here is her contribution.

Berlin distinguishes between verbal and ostensive definition. Verbal definition defines a symbol conventionally in terms of other words, for example, defining 'bachelor' to mean 'unmarried man'. Ostensive definition defines a symbol by association with something presented, i.e. a symbolic expression is attached to a characteristic given in experience or to a combination of such characteristics whose instances it then classifies' (Berlin I937: 73). For example, defining 'scarlet' by pointing at a particular patch of color (see also Schlick I936: 34I. This distinction was discussed, less favorably, by Wittgenstein in his 1933-34 lectures [I964: I]). Berlin argues that verbal definition depends, at bottom, upon ostensive definition (I937: 7I-72). As Moritz Schlick put the same point, 
[i]t is clear that in order to understand a verbal definition we must know the signification of the explaining words beforehand, and that the only explanation which can work without any previous knowledge is the ostensive definition. We conclude that there is no way of understanding any meaning without ultimate reference to ostensive definitions. (Schlick I936: 342)

Such a view is a kind of verificationist logical atomism, according to which words and their propositional correlates can be analyzed until they bottom out in atoms that are directly related to the world. This is not plausible globally, for we must explain how a practice of ostensive definition could get off the ground in the absence of any meaningful means of communication. However, Kneale's argument below only requires the weaker claim that in some important cases terms have an ostensive definition.

With this notion of ostensive definition in place, Berlin claims that, just as there is truth in virtue of meaning arising from linguistic convention, so there can be truth in virtue of ostensive meaning. He argues that we are presented not only with features but also with relations between them. As such, there are propositions concerning the relations between features that are true in virtue of their ostensive definition-true in virtue of the meaning they acquire from direct presentation in experience (that is: the sentences expressing those propositions are true in virtue of ostensive definition). Such a proposition

asserts some relation between empirical characteristics or universals which is necessary, but not rendered so by definition: for instance, 'this pink (shade) is more like this vermilion than it is like this black' . . . where pink, vermilion, black . . . 'more like' . . . are or could be defined ostensively, i.e. by pointing. One perceived instance of such complexes suffices to demonstrate that all past or future instances of the constituent universals are related by the same relation as those in the given instance . . . The logical relation of the colour names are determined by the order of the shades in a scale or series which is itself directly perceived or 'given'. (Berlin $1937: 76$ )

Berlin contends that sentences purporting to express the contradictories of such propositions are not self-contradictory, hence these propositions are not logical or analytic truths. But he takes the contradictories of these propositions to be inconceivable, hence these propositions to be necessary.

Such examples resemble Kneale's metaphysical propositions. They are necessary yet not logically necessary, and they arguably concern 'the most general characteristics of reality and the necessary relations between them'. The meanings of the constituents of these propositions are taken to arise from a direct relation to features of the empirical world. Temporal and spatial relations, and sensory qualities such as color are, it is claimed, given directly in experience, and terms for them are not definable verbally or via linguistic conventions. There may be a convention to use the symbol 'will' rather than 'was' for future tense, but the 
thought is that the relations between future, present and past tenses, whatever symbols we use for them, are given to us in experience.

This provides a candidate explanation for the inconceivability of the contradictories of metaphysical propositions: they go against the meanings of their constituents. The meanings of the terms are fixed by a relation to empirical reality-including not only the features associated with each term (e.g., a particular shade with 'scarlet'), but also the relations between different features (e.g., that scarlet is more like pink than yellow). As such, to conceive of the opposite (e.g., that scarlet is more like yellow than pink) is in violation of the very meanings of the terms. But then, how can we conceive of such a scenario at all? It would be like trying to conceive of a married bachelor.

There are other reasons to think that we fully understand propositions about color only by having some direct color experience. For example, a similar idea was famously developed by Frank Jackson (I986): Mary is missing something in her knowledge of redness if she does not leave her grayscale room to see some red things. Nevertheless, one might puzzle over the additional claim that facts about certain relations between colors are also thereby presented in experience. Is it really through direct experience that we come to know that red is more like pink than yellow? Could we not come to know each color independently, and then subsequently infer or otherwise work out-independent of a particular color experience, and in addition to the experiences in which we acquire our knowledge of the individual colors-the relations between them? Kneale and Berlin do not discuss this worry, but it seems to me that there is a reasonable response. On their view, the meanings of these color terms are not subject to analysis-they have ostensive, not verbal, definitions. Hence, they do not have the kind of structure that would be amenable to a certain kind of inferential connection between them. For example, one could not argue: pink is defined as a mixture of white and red; yellow is primitive; so red is more like pink than yellow because red is part of pink and not of yellow. If we cannot work out color relations by this kind of inference, the alternative would seem to be that we have to see them. If you have seen red, pink, and yellow, the thought goes, you must also have seen-even if you did not explicitly realize it at the time-that red is more like pink than yellow. That is just part of what it is to understand what red, pink, and yellow are.

I think this is a plausible line of argument for metaphysical propositions concerning ranges of sensory qualities. I am less sure how to extend it to temporal and spatial structures. One option might be to draw on Kant's arguments, from the Transcendental Aesthetic of the Critique of Pure Reason (I998), that our most basic representations of space and time are not concepts but intuitions: singular, immediate representations of things. Such representations are not subject to conceptual analysis, and structural features of space and time are thereby presented to us wholesale, with our initial presentation of space and time themselves. Such a view, however, if to be of use to Kneale, would need to be disentangled from Kant's other claim that these representations are not derived from sense experience and give rise to a priori knowledge of the structures of space and time. 


\section{Kneale’s Argument: Why Metaphysical Propositions Are Not A Priori}

Metaphysical propositions, for Kneale, are metaphysically but not logically necessary. Kneale seeks a further characterization of them, which renders them knowable only a posteriori.

The line of argument goes via the contradictories of metaphysical propositions. What are we to make of them? Berlin proposed that they are meaningless and hence that metaphysical propositions (propositions true in virtue of ostensive meaning) are a priori:

[I]nvited to conceive of a world in which the shades we call pink, red, black, occurred in some order other than that presented in ours, we must say that we cannot do so: not because of a failure of imagination but, because it is inconceivable: the invitation is itself nonsensical . . . But if the contradictories of these are neither self-contradictory, nor straightforwardly false, what are they? We can only answer that they seem meaningless. Meaningless not because they offend against the rules of a particular language, for they conform to them: but, because while they appear to state something, what they state is, in fact, inconceivable; i.e. they state nothing whatever. (Berlin 1937 : 77-78)

For Berlin, we do not need empirical verification of metaphysical propositions, because it does not even make sense to suppose that they are false. While Berlin does challenge the equivalence of necessity and a priority on the one hand, and analyticity on the other, he retains the equivalence of necessity and a priority.

On the contrary, Kneale argues that the contradictories of metaphysical propositions are not meaningless:

For it seems to me that we must know what a proposition means before we can know that it is necessarily false, just as we know what it means before we can know that it is self-contradictory. (Kneale I938: 264)

I find this point utterly convincing and have argued the case for contradictions at more length elsewhere (Leech 2015). While such propositions, or the sentences expressing them, may violate the meanings of their constituents, hence explaining their inconceivability, we still know the meanings of those constituents, and they are still put together in a grammatical way.

Kneale's discussion of the next option leads into the core of her argument. She argues against the suggestion that the contradictories of metaphysical propositions are a priori inapplicable. In her framework, applicability is a matter of exemplification in empirical reality; a proposition is exemplified in empirical reality just when its terms are instantiated in empirical reality and it is true. One might think that applicability should only be a matter of whether the terms of the proposition are instantiated, not whether the proposition is true. However, the condition of truth is required to make sense of why one might take the 
contradictories of metaphysical propositions to be inapplicable, e.g., that red is more like yellow than pink; for the terms of such a proposition are instantiated, even though as a whole it is necessarily false. A proposition is a priori applicable, then, just when it is a priori, and hence necessary, that it is exemplified in empirical reality. (Only the direction from necessity to a priority is challenged here, not that from a priority to necessity, so we can allow the move from a priority to necessity.) A proposition is a priori inapplicable just when it is a priori that the proposition is not exemplified in empirical reality. Kneale also assumes that a proposition $p$ is a priori applicable if and only if the contradictory of $p$ is a priori inapplicable. Finally, a proposition is existential just when the proposition entails whether or not its terms are instantiated (Kneale I938: 264-65).

How does a priori applicability relate to a priori knowledge? If it is a priori applicable that $p$, then it is a priori that the terms of $p$ are instantiated and $p$ is true. If it is-as follows-a priori that $p$ is true, this is tantamount to the a priori knowability of $p$. So, a priori applicability entails a priori knowability. It is unclear whether the reverse entailment holds, for one might think there could be cases where one could know a priori that $p$ but not know a priori that the terms of $p$ are instantiated (perhaps a priori truths concerning very big numbers in a universe of unknown size), but I shall set this question aside, as it is not crucial for the argument that follows.

For Kneale, logical propositions are a priori applicable,

for whatever kind of universe may be conceived, it must be described by one or more true propositions and it will be true that these propositions cannot be both true and false and that they must be false, if they are not true. (Kneale I938: 265)

Her point is not merely that logical truths would be true no matter what, but that their terms would be instantiated. If logical truths are about propositions-e.g., no proposition can be both truth and false-then the term 'proposition' would always have application, because no matter what, there would be propositions describing how things are.

However, Kneale argues, metaphysical propositions are different. The first step of her argument is supposed to establish that all known metaphysical propositions contain, besides logical constituents, only constituents 'with which we have direct acquaintance in empirical reality' (Kneale 1938: 265). This is presented as following from the fact that metaphysical propositions are synthetic:

[A]ll the metaphysical propositions we know do have exemplification in empirical reality and this must be so because, since metaphysical propositions are synthetic, their terms must be understood apart from the propositions if the propositions are to be known. For if the constituents of these propositions could be defined in terms of each other, the propositions concerning their relations would be analytic. Consequently, all the metaphysical propositions which we know 
contain besides logical constituents only constituents with which we have direct acquaintance in empirical reality. (Kneale I938: 265)

Why conclude that we have direct acquaintance with the nonlogical constituents of metaphysical propositions as exemplified in empirical reality, just because they are synthetic? One might suppose that the constituents of a synthetic proposition could be given verbal definitions elsewhere, and then be combined into a meaningful, synthetic proposition. For example, plausibly, I can know that Jimmy is a bachelor without needing direct acquaintance with some property of bachelorhood (perhaps without needing direct acquaintance with Jimmy). However, how could one account for the necessity of a synthetic proposition with ostensively defined constituents, or for the inconceivability of its contradictory? As there is no deep connection between the definitions, and no contradiction in putting together the constituents of the contradictory, it is hard to see where any necessity could arise from in the former case, or incompatibility in the latter case. The thought seems to be that if we are to find another kind of incompatibility, besides contradiction, we will not find it in the words and their definitions, but in the things our words are about or express, hence, in the things with which we have direct acquaintance. Indeed, Kneale suggests this move from linguistic rules to the things our words are about when she writes of the tense rules that

[e]ven though the rules may be expressed in linguistic form . . . they do not express primarily our determination to use 'was', 'is' and 'will be' in accordance with the rules, but the fact that, since we use them as we do, the relations between sentences containing them must be so and that whatever expressions we choose to use as equivalent to 'was', 'is' and 'will be', respectively, the rules governing their use must be the same. (Kneale I938: 263-64)

The terms expressing nonlogical constituents of metaphysical propositions must be understood via direct acquaintance with the things to which they apply in empirical reality, so these terms have an ostensive, not a verbal, definition.

The above draws out that, for Kneale, there are constituents of propositions with which we have direct acquaintance in empirical reality. This suggests that she has a Russellian conception of propositions-propositions are constituted from worldly things, objects and properties, say, rather than abstract or mental representations of worldly things. Indeed, this may help us to make sense of the terms of a proposition having 'instantiation'. One usually thinks of properties as the kinds of things to be instantiated. If properties themselves are constituents of propositions, then it makes straightforward sense that the terms of a proposition may be instantiated or not. What this does then commit Kneale to is the existence of uninstantiated properties; for, as I discuss later, she allows that there can be propositions containing uninstantiated terms.

The second step of Kneale's argument purports to show that, therefore, metaphysical propositions are not a priori applicable. For they are also not existential: 
$[\mathrm{M}]$ etaphysical propositions are not existential. They do not themselves entail anything about the instantiation of their terms. (Kneale I93 8: 265)

Metaphysical propositions concern general, structural facts about the world, and general statements are not existentially committing. To take Kneale's examples, general rules for tensed propositions or sentences do not require, or preclude, the existence of any such propositions or sentences; and general propositions concerning the structure of the color spectrum do not require or preclude anything actually being colored. As metaphysical propositions are not existential, they can be true without their terms being instantiated in empirical reality (here arises the commitment to uninstantiated properties). Kneale argues that, therefore, it is possible that there are true yet unknown metaphysical propositions. If we need direct acquaintance with the referents of the constituents of a metaphysical proposition in order to understand it, but if its constituents are not instantiated in empirical reality, then we could not understand the proposition, let alone know it. Nevertheless, as a nonexistential proposition, it could still be true.

Kneale presents two ways in which metaphysical propositions may be true and unknown:

It seems possible, therefore, that there may be true metaphysical propositions, the terms of which have no instantiation and about which, therefore, we know nothing. On the other hand, it is conceivable that the terms of the metaphysical propositions we do know should not have instantiation. In that case the metaphysical propositions might be said to have no application. For example ... in a universe in which there was no colour, Mr. Berlin's metaphysical propositions about the relations of colour would have no application. (Kneale I938: 265)

(I) It is possible that there are true metaphysical propositions that are not exemplified in empirical reality, hence, possible that there are true metaphysical propositions that we do not know. (2) Of the metaphysical propositions we do know, it is possible that they might not have been exemplified in empirical reality, and hence possible that we did not know them.

Finally then, we cannot know independent of experience which metaphysical propositions are exemplified in empirical reality-for that we need direct acquaintance with their constituents. That is, we need particular empirical experience. So metaphysical propositions are not a priori applicable. The same argument seems also to show that metaphysical propositions are not knowable $a$ priori, but rather only knowable empirically, if at all. For we need direct acquaintance with-particular empirical experience of-what the metaphysical propositions are about to be able to understand and know them.

One can find a similar point, briefly put, in Kneale's later work:

No doubt every proposition which is analytically true can be known $a$ priori and every proposition which can be known a priori is necessary. 
But it is by no means obvious that the converse relations hold. . . it is at least conceivable that there are ['necessary truths (i.e. truths without alternatives) which cannot be known a priori']. We commonly admit that there are truths of mathematics which no one in fact knows, and it does not seem absurd to suggest that there may be necessary truths about unperceived qualities or relations which no human being can ever know because (as Locke might say) none has the requisite ideas. (Kneale and Kneale I962: 637)

In response, while one may grant that we need particular empirical experiences to acquire certain (perhaps all) concepts, one could still deny that all propositions containing these concepts are thereby knowable only a posteriori. For example, we might grant that the concept red can only be properly acquired through experience of red things, but still suppose that a proposition such as red is a color is a priori. Is Kneale making such a mistake-confusing conditions of concept acquisition with the kind of knowledge one can have of propositions involving such concepts once acquired? On the contrary, her claim is not that any proposition containing ostensively defined constituents must be $a$ posteriori, but rather a special class of propositions: necessary, synthetic propositions about the general structure of the world. So, although our grasp of red is a color may require a certain kind of experience, in order to acquire the concept red, this is not obviously a metaphysical proposition in Kneale's sense, for it does not concern a structural relation between colors.

Nevertheless, metaphysical propositions might yet appear a priori. Kneale discusses a class of propositions which are such that if one is in a position to understand them, one is also thereby in a position to know them. Surely this is $a$ priori if anything is.

Again, I think this is to misunderstand Kneale. Take a priority to be a matter of knowability without the requirement for particular empirical confirmation, and the a posteriori to require particular empirical confirmation. So, for example, one cannot know that grass is green without a particular kind of empirical confirmation (e.g., seeing grass under ordinary conditions) but one can know that $2+2=4$, without particular empirical confirmation.

At this point, I find Timothy Williamson's distinction between evidential and enabling roles of experience to be helpful. Roughly: experience plays an evidential role in knowledge that $p$ if it provides evidence for believing that $p$; it plays an enabling role if it provides the opportunity to acquire concepts required to grasp $p$ :

Experience is held to play an evidential role in my visual knowledge that this shirt is green, but a merely enabling role in my visual knowledge that all green things are coloured: I needed it only to acquire the concepts green and coloured, without which I could not even raise the question whether all green things are coloured. (Williamson 2007: I65)

A priori knowledge is standardly taken, Williamson explains, to be incompatible with an evidential, and compatible with an enabling, role for experience. Hence, 
experience is usually taken to be merely enabling in cases of a priori knowledge, and strictly evidential in cases of a posteriori knowledge.

Consider Kneale's metaphysical propositions. In order to be in a position to grasp them, one must have particular empirical experiences, hence, experience plays an enabling role. But it does not play a merely enabling role; the experience also provides the exact kind of empirical confirmation required for a posteriori knowledge of these propositions. These propositions are known by empirical experience already in the kind of experience that is required for us to grasp them. One might put the point: in such cases, the experience is a common cause of both concept possession and knowledge. So yes, metaphysical propositions resemble the a priori, because if one is in a position to grasp them, one is also thereby in a position to know them. But they also resemble the a posteriori because it is only possible to know them through particular empirical confirmation. The reason why this is so does, admittedly, seem rather different to standard cases of the $a$ posteriori. But it is also importantly different to standard cases of the a priori. At worst, we might best understand Kneale as having found a class of cases that cast doubt on the exhaustiveness of this distinction.

Indeed, this is reminiscent of Williamson's discussion of whether certain kinds of counterfactual judgment-including the kind that gives us knowledge of metaphysical modality-are a priori or a posteriori (Williamson 2007:165-69). Given an understanding of a priori knowledge according to which it is incompatible with an evidential, and compatible with an enabling, role for experience, it is unclear, for Williamson, how to classify the kind of knowledge of counterfactuals that he takes to be based in the imagination. For while experience does not play an obviously evidential role in cases of such knowledge, it also seems to be playing more than a merely enabling role. In brief, past experience is taken to feed into our capacity to appropriately imagine various scenarios on the basis of which to make counterfactual judgments. Ultimately, Williamson suggests that the distinction between a priori and a posteriori is 'handy enough for a rough initial description of epistemic phenomena', but 'out of place in a deeper theoretical analysis, because it obscures more significant epistemic patterns' (2007: I69). He favors the introduction of a category of 'armchair knowledge' into which modal knowledge may fall.

One might take Kneale, like Williamson, to be introducing a category of knowledge that bears traits of both a priori and a posteriori knowledge. However, there is an important difference which may help us to understand Kneale better. Experience plays an enabling-albeit not a merely enabling-role in knowledge of metaphysical propositions, for, according to Kneale, it is only through experience that we can grasp their nonlogical constituents. But whereas for Williamson experience does not play a properly evidential role in modal knowledge-because it contributes by improving our imaginative capacities-I contend that for Kneale it does. How do we come to know that scarlet is more like pink than yellow? We experience colors and their relations. How do we come to know tense rules such as rules I and 4 ? We directly experience temporal relations, and thereby come to have knowledge of the temporal structure of the world. So, when it comes to knowledge of metaphysical propositions, one and the same experience is both 
enabling — in allowing us to acquire the relevant concepts—and evidential—in providing the evidence required for knowledge. In such cases, evidential role should trump enabling role, for it seems wrong to describe a case of knowing that $p$ on the basis of a direct empirical experience providing evidence for $p$ as a case of a priori knowledge.

To sum up: metaphysical propositions are metaphysically necessary and general (not existential). They can only be grasped and known via particular empirical experience (they have ostensive definitions). As a consequence, they are not knowable a priori. That they require ostensive definition explains why their contradictories are inconceivable; their contradictories go against the (ostensive) meaning of the terms. But this does not render the propositions themselves knowable a priori, for the reasons canvassed above. All this being so, the necessity of metaphysical propositions is not to be explained in terms of analyticity or verbal definition, which would allow them to be a priori, but must rather be explained in terms of something to do with aspects of the world that we can only access through direct experience.

Before exploring the more obvious comparison with Kripke, it is worth pausing to note that something similar to Kneale's view has appeared more recently, in E. J. Lowe's work on modal epistemology (although he professes to be 'somewhat sceptical about the very idea of a posteriori necessary truths' [Lowe 20I2: 920]). Lowe takes metaphysical necessity to have its source in the essences of things, where to give the real definition of a thing is to reveal its essence (Lowe 20I2: 939, 94I). As is standard, real definition is contrasted with verbal definition (or nominal definition): real definition is 'a definition of a thing'; nominal definition is 'a definition of a word or phrase' (Lowe 20I2: 935). However, Lowe also introduces ostensive real definition. That is, some things, such as colors, can only be defined ostensively:

I think we can provide red with an ostensive real definition. I can point to a colour-sample and say 'red is this colour'. (Lowe 20I 2: 942)

When it comes to our knowledge of a necessary truth about color, in particular, that a uniformly colored surface is not at once both red and green, he thus writes,

[i]n grasping what red is and what green is, by grasping ostensive real definitions of them, we thereby also grasp their mutual exclusivity, and thus that what is red is necessarily not green. There is no formal logical deduction of this available ... But, I suggest, we can still infer, with equal assurance, from appropriate ostensive real definitions of red and green, that no uniformly coloured surface can have both of these colours simultaneously. (Lowe 20I2: 943)

But for the specification of real, rather than nominal, definition, this could almost be taken from Kneale's paper. How significant is that difference? It is important not to confuse the distinction between real definitions of things and nominal definitions of words. However, remember that Kneale is concerned not only with words, but with 
the propositions that sentences made up of words express, and with the constituents of those propositions. We have seen that it is reasonable to interpret Kneale as taking propositional constituents to be worldly, in which case, definitions of those constituents will, after all, be definitions of things (not words), and thereby functionally equivalent to real definitions. Hence, Kneale anticipates something similar to Lowe's modal epistemology. What Kneale lacks, however, is a developed account of the source of metaphysical necessity in the essences of things.

\section{Kneale and Kripke}

There are two features of Kripke's view that are particularly salient for comparison. First, Kripke argues against a descriptivist theory of names and natural kind terms. He argues that the meanings of terms such as 'Hesperus' and 'water' are not to be understood as equivalent to descriptions such as 'The evening star' and 'The clear liquid that runs in rivers. . $\therefore$ On the contrary, these expressions are rigid designators (Kripke I98I: 49). As a consequence of this, certain sentences fail to be analytic and necessary, such as 'Hesperus is the evening star', and others are necessary even though they are neither analytic nor a priori, such as 'Hesperus is Phosphorus' and 'Water is $\mathrm{H}_{2} \mathrm{O}$ ' (Kripke I98 $\mathrm{I}$ : IO2-5). Second, the explanation of these necessities has something to do with the things that are referred toVenus, water-rather than analyticity of the sentences used to express them. For example, it is necessary that Hesperus is Phosphorus because Venus is necessarily self-identical; in the actual world both 'Hesperus' and 'Phosphorus' happen to refer to Venus, and so 'Hesperus is Phosphorus' expresses a necessity. As Kripke puts it, 'the planet Venus is the planet Venus and it doesn't matter what any other person has said in this other possible world' (I98I: IO2): it does not matter if in some other world some other person uses the names 'Hesperus' and 'Phosphorus' differently; all that matters is that we use them to rigidly refer to Venus, and that necessarily, Venus is Venus.

These features of Kripke's view are not quite the same as, but correspond strikingly to, key features of Kneale's view. Kneale endorses an account of the meanings of certain terms that takes them to have ostensive definitions rather than verbal definitions. This corresponds to Kripke's rejection of a descriptivist theory of names. The targets are different: Kripke is writing about names and natural kind terms; Kneale is writing about terms corresponding to certain structures in the world, such as tenses and color terms. But in both cases the thought that such terms could be given a definition using more words is rejected.

The second point of comparison is that, having moved away from a certain kind of linguistic explanation of the necessities under consideration, both Kneale and Kripke turn toward an explanation of the necessities in terms of the things themselves. Again, specifics are importantly different-Kripke appeals to facts about identity and essence, Kneale appeals to certain structures and relations between qualities-but in both cases it is these things, such as the identity of Venus, or the color structure, that play a crucial role in determining the necessities. Given the story each tells about the kinds of propositions or sentences we can use to represent these necessities, we cannot access the necessities via analysis of the propositions'/sentences' meaning. For Kneale, the relevant 
propositions contain ostensively defined constituents, which one can only grasp if one has certain direct experiences, and which are not analyzable. For Kripke, the relevant sentences contain rigid designators which do not contain or entail a description, and so are also not analyzable. In both cases, the only way to come to know the necessity is to have a particular experience: one needs to experience the colors; one needs to show empirically that the heavenly body shining in the morning is the very same thing as the heavenly body shining in the evening.

One should not also say: in both cases, the only way to grasp the content of the proposition or sentence is to have a particular experience. For Kneale, one must experience the colors, not only to learn about necessary color structures, but even to grasp color terms at all. Not so for Kripke. Although he eschews giving a full, positive theory of reference (I98I: 93), he does sketch some options for how the reference of a rigid designator might be fixed and passed on. For example, ostension might be used, or one might use a contingent description to pick something out initially that would then be rigidly designated even once that description becomes false (Kripke I98I: 96). What one means by a name or term further down the line may then depend on causal-historical links between that use of the expression and that initial 'baptism' (Kripke I98 I: 95). For Kneale, the same direct experience that allows one to grasp the terms also allows one to learn the necessities. For Kripke, the kind of experience that allows one to learn the necessities is distinct from the kind of engagement in the causal history of the use of a term that allows one to grasp the sentences expressing the necessities. This, then, goes some way to showing the additional step that Kripke took. Kneale saw a way to decouple metaphysical necessity and a priority, but her account of the meanings of the crucial terms is still to a certain extent tied up with the knowledge of those necessities: grasping their meaning and learning the necessities both involve the same direct empirical experience. Kripke goes further, in completely disconnecting our understanding of a necessity such as 'Hesperus is Phosphorus' from our knowledge of it.

Interestingly enough, Kripke does briefly discuss color. He suggests that the reference of 'yellow' may be fixed by a certain kind of sensory experience, but that it should not be taken to be synonymous with a description of such an experience (likewise, Lowe 2012: 942). For things could be yellow without us experiencing them, or if we had had very different sensory capacities such that we no longer had the same kind of experience when presented with yellow things:

The proper account, on the present conception is, of course, that the reference of 'yellowness' is fixed by the description 'that (manifest) property of objects which causes them, under normal circumstances, to be seen as yellow (i.e., to be sensed by certain visual impressions)'; 'yellow', of course, does not mean 'tends to produce such and such a sensation'; if we had had different neural structures, if atmospheric conditions had been different, if we had been blind, and so on, then yellow objects would have done no such thing. (Kripke I98 I: I40n7I)

This brings out nicely the difference from Kneale. Both agree that 'yellow' lacks a verbal definition. Kneale (and Berlin) argue that it has an ostensive definition. 
They do not take a verbal description of a certain sensory experience to be the definition of 'yellow', but such an experience is nevertheless definitive of it in some sense. Kripke takes the experience they took for an ostensive definition to be a case of reference-fixing.

It is also illuminating to compare Kneale and Kripke on uninstantiated terms. Kripke presents an argument concerning unicorns:

It is said that though we have all found out that there are no unicorns, of course there might have been unicorns. Under certain circumstances there would have been unicorns. And this is an example of something I think is not the case. Perhaps according to me the truth should not be put in terms of saying that it is necessary that there should be no unicorns, but just that we can't say under what circumstances there would have been unicorns. (I98I: 24)

Just as tigers are an actual species, so the unicorns are a mythical species. Now tigers ... cannot be defined simply in terms of their appearance; it is possible that there should have been a different species with all the external appearances of tigers but which had a different internal structure and therefore was not the species of tigers. . . . Now there is no actual species of unicorns, and regarding the several distinct hypothetical species, with different internal structures (some reptilic, some mammalian, some amphibious), which would have the external appearances postulated to hold of unicorns in the myth of the unicorn, one cannot say which of these distinct mythical species would have been the unicorns. If we suppose, as I do, that the unicorns of the myth were supposed to be a particular species, but that the myth provides insufficient information about their internal structure to determine a unique species, then there is no actual or possible species of which we can say that it would have been the species of unicorns. (I98I: I 56-57)

We might interpret Kripke as follows. A term such as 'tiger' acquires its meaning through association with some sample of a kind, say, a tiger. A tiger is a mammal. Hence 'tiger' refers to a particular species of mammal. 'Unicorn' purports to be a kind term also referring to an animal species. But there are no unicorns, hence there is no sample of the kind-no unicorn-to fix a reference for the term. Now, of course we could cook up a descriptive meaning, such as 'horse-like animal with a single forehead horn', but then 'unicorn' would no longer be a natural kind term analogous to 'tiger' or 'horse'. But if what 'unicorn' refers to must, instead, be fixed by some relation-perhaps using ostension or a contingent descriptionto an actual token of the kind, then it has no reference, and it is not possible for us, in our actual world, to express the possibility properly that there might have been unicorns. It is thereby indeterminate what kind of thing a unicorn would be, hence we cannot know one way or another whether there might have been 
unicorns, because we do not know what it would be for there to be unicorns (Dummett [I996: chapter I4] disagrees; see Reimer I997 for discussion).

Compare Kneale on uninstantiated metaphysical propositions:

[Metaphysical propositions] do not themselves entail anything about the instantiation of their terms. It seems possible, therefore, that there may be true metaphysical propositions, the terms of which have no instantiation and about which, therefore, we know nothing. On the other hand, it is conceivable that the terms of the metaphysical propositions we do know should not have instantiation. In that case the metaphysical propositions might be said to have no application. For example, in a static universe the propositions concerning the becoming true and false of propositions would have no application, and, in a universe in which there was no colour, Mr. Berlin's metaphysical propositions about the relations of colour would have no application. (Kneale I938: 265)

For Kneale, propositions about temporal and color relations depend upon ostensive definition of instantiated qualities and relations. Kneale argues that had we lived in a world without time or color, we would not have known anything of the necessary propositions about time and color, because they would have had no application, and hence we would have had no means to come to know them. Again, Kripke's argument is different, but in the same spirit: given that we live in a world without unicorns, we cannot know any metaphysical propositions about unicorns (e.g., that they are mammals, or reptiles, or whatever), because the term 'unicorn' has no application, so there are no instances to determine, or to show us, what a unicorn is.

So, Kripke and Kneale are similar. But does Kripke's view constitute a wholly positive advance? Kneale and Kripke both separate the necessary from the $a$ priori. Kripke's additional decoupling of the grasping and knowing of metaphysical necessities is also a crucially important philosophical innovation. However, there is at least one respect in which Kneale's view-lacking this latter distinction-arguably does better.

Conceivability accounts in modal epistemology have a long and rich history. This history is also a checkered one, insofar as substantial questions have been raised against such accounts (see, e.g., Gendler and Hawthorne 2002; Vaidya 20I7). One key issue concerns the relation between conceivability and modality: why suppose that what we are able to conceive of bears any useful relation to what there can and cannot be? If one takes metaphysical modality to have its source in conceptual connections, and takes conceivability to be constrained by those same conceptual connections, then there is a (relatively) easy answer to that question available. But if one takes metaphysical modality to have its source in thingsindependent of how we think of them-the question has considerable bite. One might retort that if one favors the latter kind of view, then one ought to reject conceivability-based modal epistemologies. But such a rejection is not so straightforward. For one thereby incurs the challenge to come up with something 
better. And it is not as easy to get away from conceivability as might first appear. For example, if one takes metaphysical necessity to have its source in the essences of things, one might take knowledge of necessity also to depend upon knowledge of essence, but whence knowledge of essence? In at least some cases, the answer seems to revert back to conceivability. For example, for Wiggins (200I: esp. I I ) the essence of something $x$ and our ability to conceive of $x$ in counterfactual scenarios are closely entwined. In short: we might take conceivability approaches to modal epistemology to be a pretty compelling default.

In section 2, I note that Kneale appeals to the principle that if it is necessary that $p$, then it is inconceivable that not-p. But she not only appeals to this principle; she has the resources to defend it, and thereby to show how conceivability-based modal epistemologies can be made compatible with the view that metaphysical modality has its source in mind-independent reality. She can explain the inconceivability of metaphysical impossibilities, because metaphysical necessity is still in some way connected with meaning: although a metaphysical impossibility is not a contradiction, it still violates the meanings of the terms in an important way, given that the meanings of those terms are connected by ostension to the natures of the things they are about.

Wright $(2002 ; 2018)$ has argued that Kripke was also, surprisingly, committed to a counter-conceivability principle. In cases where the negation of some putative metaphysical necessity, such as that water is $\mathrm{H}_{2} \mathrm{O}$, appears to be perfectly conceivable, Kripke suggests that it is really something else that is similar of which we are conceiving. Conceiving of the negation of a metaphysical necessity proper is disallowed:

Kripke's response to protect the necessity of true identifications of the relevant kind from the depredations of apparently lucid counterconceivings is to insist on a distinction between conceiving of $X$ not being $F$ and conceiving of an epistemic counterpart of $X$ not being $F$. Something which presents as water in all (surface) respects covered by our pre-theoretic conception of water-the indicators that, prior to the scientific investigation, we would use to classify a sample as one of water-need be no more than an epistemic counterpart of water. (Wright 201 8: 269-70)

It remains a mystery, for the Kripkean, why we should not be able genuinely to conceive of metaphysical impossibilities, hence this appeal to counterconceivability looks suspect. Surely Kripke should say something more like the following:

[W] hen it is metaphysical possibility that is at issue, why not just recognize that some metaphysical impossibilities may be perfectly lucidly conceivable-precisely because the impossibilities concerned are not grounded in the first place (purely) in our concepts of the events, states, or stuffs, etc. concerned? (Wright 20I 8: 279) 
Without further argument, Kripke's appeal to a conceivability principle is unjustified, for he allows no connection between what we grasp when we understand his a posteriori necessities and our knowledge of them.

In sum, Kneale separates metaphysical necessity and the a priori, but not so far as to also separate the conditions under which we can grasp and know necessities. This leaves room for a connection between necessity and conceivability. Her view also moves away from a conventionalism according to which necessity-and our knowledge of it-is connected to merely verbal and linguistic conventions. Thus, her view offers an attractive balance between a robust grounding of metaphysical necessity in the world, and a long-standing and continually compelling connection between modality and conceivability. Kripke takes that more robust grounding of metaphysical necessity further, in also separating our grasp of necessities from our knowledge of them. This has the downside of-at least prima facie-ruling out conceivability as an option in our modal epistemology. It also causes problems where Kripke's own arguments appear to depend upon a counter-conceivability principle. It remains for the Kripkean either to defend the use of such a principle in Kripkean context, or to reshape the relevant arguments, and the epistemology, so they no longer rely upon it.

\section{Conclusion}

In contrast to the usual story, I have argued that the necessary a posteriori appears in the work of Martha Kneale, in the I930s. Therefore, in an account of the history of our changing understanding of metaphysical necessity and its relation to a priori knowledge, Kneale should be recognized as a landmark figure. Moreover, I have argued that Kneale's view may also provide a template for a reconciliation of traditional conceivability-based modal epistemologies, and the post-Kripkean trend for taking the source of metaphysical necessities to be in mind-independent empirical reality.

JESSICA LEECH

KING'S COLLEGE LONDON jessica.leech@kcl.ac.uk

\section{References}

Ayer, A. J. (1936) Language, Truth, and Logic. 2nd. ed. Middlesex: Penguin Books.

Berlin, Isaiah. (I937) 'Induction and Hypothesis III'. In 'Knowledge and Foreknowledge,' supplementary volume, Proceedings of the Aristotelian Society, I6, 63-102.

Bird, Graham. (2010) 'Kant's Analytic Apparatus'. In Graham Bird (ed.), A Companion to Kant (Malden: Wiley-Blackwell), I25-39.

Dummett, Michael. (1996) The Seas of Language. Oxford: Oxford University Press.

Ewing, A. C. (1940) 'The Linguistic Theory of “A Priori” Propositions'. Proceedings of the Aristotelian Society, 40, 207-44.

Gendler, Tamar Szabó and John Hawthorne, eds. (2002) Imagination, Conceivability and Possibility. Oxford: Clarendon Press.

Jackson, Frank. (I986) 'What Mary Didn’t Know'. Journal of Philosophy, 83, 29I-95. 
Kant, Immanuel. (1998) Critique of Pure Reason. Translated and edited by Paul Guyer and Allen W. Wood. New York: Cambridge University Press.

Kneale, Martha. (I938) 'Logical and Metaphysical Necessity'. Proceedings of the Aristotelian Society, 38, 253-68.

Kneale, William, and Kneale, Martha. (1962) The Development of Logic. Oxford: Clarendon Press. Kripke, Saul. (I98I) Naming and Necessity. Malden: Blackwell.

Leech, Jessica. (201 5) 'Logic and the Laws of Thought'. Philosopher's Imprint, I 5, I-27.

Lowe, E. J. (2OI2) 'What is the Source of Our Knowledge of Modal Truths?' Mind, I2I, 919-50.

Ney, Alyssa. (20I4) Metaphysics: An Introduction. London: Routledge.

Quine, Willard Van Orman. (I95 I) 'Two Dogmas of Empiricism'. Philosophical Review, 60, 20-43.

Quine, Willard Van Orman. (I953) 'Reference and Modality'. In Quine, From a Logical Point of View: Nine Logio-Philosophical Essays (Cambridge, MA: Harvard University Press), I39-59.

Reimer, Marga. ( 1997) ‘Could There Have Been Unicorns?' International Journal of Philosophical Studies, 5, 35-5I.

Rosen, Gideon. (2006) 'The Limits of Contingency.' In Fraser MacBride (ed.), Identity and Modality, Mind Association Occasional Series (Oxford: Oxford University Press), I3-39.

Schlick, Moritz. (I936) 'Meaning and Verification'. Philosophical Review, 45, 339-69.

Stadler, Friedrich and Thomas Uebel, eds. (2012) Wissenschaftliche Weltauffassung. Der Wiener Kreis. Hrsg. vom Verein Ernst Mach (I929). Vienna: Springer.

Vaidya, Anand. (2017) 'The Epistemology of Modality'. In Edward N. Zalta (ed.), The Stanford Encyclopedia of Philosophy (Winter 2017 edition). https://plato.stanford.edu/archives/ win20I7/entries/modality-epistemology/.

Williamson, Timothy. (2007) The Philosophy of Philosophy. Oxford: Blackwell.

Wittgenstein, Ludwig [192 I] (1974) Tractatus Logico-Philosophicus. Translated by D. F. Pears and B. F. McGuinness. Revised ed. London: Routledge and Kegan Paul.

Wittgenstein, Ludwig. (1964) The Blue and Brown Books. Oxford: Basil Blackwell.

Wright, Crispin. (2018) 'Counter-Conceivability Again'. In Ivette Fred-Rivera and Jessica Leech (eds.) Being Necessary: Themes of Ontology and Modality from the Work of Bob Hale (Oxford: Oxford University Press), 266-82.

Wright, Crispin. (2002) 'The Conceivability of Naturalism'. In Tamar Szabó Gendler and John Hawthorne (eds.), Conceivability and Possibility (Oxford: Clarendon Press), 40I-40. 